\title{
Non-conscious Effects of Marketing Communication and Implicit Attitude Change: State of Research and New Perspectives
}

\author{
Didier Courbet ${ }^{*}$, Marie-Pierre Fourquet-Courbet \\ Aix-Marseille Universite, IRSIC EA 4262, 13005, Marseille, France
}

\begin{abstract}
The article shows that many psychological effects of the marketing communication, sometimes called "non-conscious effects", really produce implicit attitude changes. We show that the theoretical and methodological framework of implicit attitude is well adapted to study these effects and to open new perspectives to study the persuasion in a marketing communication context. On the basis of research conducted within advertising contexts, product placement and TV sponsorship, four types of non-conscious influences are examined: a) non-conscious perception of brands, b) low-attention and forgotten exposures, c) attitude conditioning, $\mathrm{d}$ ) brand insertion into emotional contexts. While discussing the contributions and limitations of major research methodologies, we highlight new perspectives likely to further the progress of research. We open up new perspectives first to increase the ecological and theoretical validity of methodologies; secondly, to improve the validity of effects measure. At a practical level, we posit that the measures of effects currently used by advertising agencies and advertisers underestimate the effects of marketing communication campaigns. A third research perspective endeavors to better understand the links between implicit and explicit attitudes on the one hand, and behavior on the other hand. The article gives some basis to the field called by some people "neuromarketing".
\end{abstract}

\section{Publication History:}

Received: March 04, 2014

Accepted: April 12, 2014

Published: April 14, 2014

\section{Keywords:}

Advertising effects, Attitude change, Implicit measures, Implicit memory, Neuromarketing, Persuasion

\section{Introduction}

In the field of research into the influence of advertising and marketing communication, the past decade has been defined by a significant increase in the number of publications dealing with non-conscious psychological processing. There are at least two explanations for it. First, growing number of communication media (Internet sites, TV channels) and of poorly argued or non-argued commercials (web banners, TV sponsorship, and product placement in movies...) makes low-attention quickly-forgotten exposures more frequent. Furthermore, it is often thought that the reception of brand advertising and spots often occurs in an entertainment context [1], rather than one where individuals are engaged in an active search for information relating to purchasing. Brand displays and related commercials, seldom expected or sought out, are therefore seen and processed in a context where the level of attention is low or nil. The practical dimension of research on influences occurring under these circumstances is therefore rather important.

Secondly, the significant progress of research in social and cognitive psychology dealing with implicit measures, on the one hand [2] and with implicit memory and implicit cognition $[2,3]$ on the other hand, prove that an important part of the psychological activity involved in thinking, judgments, feelings and behaviors is unconscious [4]. Advertising and marketing researchers have applied these new concepts and methodologies in order to better understand the nonconscious influence processes of marketing communication and the memory, attitudinal and behavioral effects $[5,6]$. However, these latest research works include a significant amount of different terminology, with definitions that sometimes change from one research to the next, thus creating a certain amount of conceptual confusion. Reference is made to "incidental exposure", "subliminal perception", "automatic processing", "nonconscious influence" etc. This lack of clarity is also contributed to by an equal use of highly different methodologies.

The first objective of the article is to show that the theoretical framework of the implicit attitude makes it possible to clarify this field of research. Secondly, because the theoretical and methodological framework of the implicit attitude is well adapted to study these types of effects, we show that research on the implicit attitudes opens new perspectives to study the persuasion in a marketing communication context. In the first part of the article, we analyze four types of research within the implicit attitude theoretical context: a) non-conscious perception of brands, b) low-attention and forgotten exposures, c) evaluative conditioning, d) brand insertion into emotional contexts. We show that these four types of effects produce changes of implicit attitude. In the second part of the article, we draw up a critical survey of current methodologies and open up new perspectives aimed at improving the theoretical and ecological validity of methodologies. This part deals with new research perspectives able to provide a better insight of non-conscious influences of marketing communication.

*Corresponding Author: Dr. Didier Courbet, Professor of Communication Sciences, Aix-Marseille University, IUT- Département techniques de commercialisation, 413 Avenue Gaston Berger- 13625 Aix-en-Provence Cedex 1 - France, E-mail: didier.courbet@orange.fr

Citation: Courbet D, Fourquet-Courbet MP (2014) Non-conscious Effects of Marketing Communication and Implicit Attitude Change: State of Research and New Perspectives. Int J Journalism Mass Comm 1: 103. doi: http://dx.doi. org/10.15344/2349-2635/2014/103

Copyright: (c) 2014 Courbet et al. This is an open-access article distributed under the terms of the Creative Commons Attribution License, which permits unrestricted use, distribution, and reproduction in any medium, provided the original author and source are credited. 
After a critical assessment of methodologies currently used in this field of research, we propose new perspectives aimed at enhancing the theoretical, ecological and predictive validity of methodologies and dependent variable measures. An enhanced methodological validity is of a two-fold major interest. First, a scientific interest as far as theoretical advances in the non-conscious influences closely depends on the development of new valid methods. Secondly, at a practical level, because the measures of effects currently used by advertising agencies in copy-testing, post-test or tracking underestimate the effects of marketing communication campaigns.

Greenwald and Banaji [7] defined implicit attitude as "introspectively unidentified (or inaccurately identified) traces of past experience that mediate favorable or unfavorable feeling, thought or action toward social objects". Within a marketing communication context, we are interested in the antecedents on the one hand, and in the formation and change processes on the other hand, and finally, in the consequences of the implicit attitude towards a brand. Thus, the article focuses more extensively on non-conscious processes operating in the persuasion process. According to Dijksterhuis et al. [8] and Cheesman and Merikle [9], we start from an initial definition of the "non-conscious", which will be examined and refined over the article. Psychological activities (stimuli processing, processes...) are non-conscious when an individual is unable to intentionally produce a symbolic answer (e.g. a verbal reply) relating to these activities. An important part of the processes which underlie the implicit attitude change are automatic and therefore non conscious [10]. We limit the scope of this article to the three main types of marketing communication whose non-conscious influences have been specifically examined: advertising in the media and on the Internet, product placement in movies and sponsorship in the media.

\section{Four Types of Non-Conscious Influence Which Produce Implicit Attitudes Change}

Whilst always tackling processing antecedents, processing themselves and their consequences, we examine four different types of models of non-conscious influences. These four types of processing produce implicit attitudes. They are classified in the following way: first the simplest processing, then the more complex processing. We will focus at first on unsophisticated psychological processing, i.e. those which take into consideration a minimum set of information, and then move on to more elaborate processes where the working memory takes into account more information. The first type refers to influences following non-conscious perception of a brand. The second type refers to influences due to the low-attention and instantly-forgotten exposures to a brand, where a single stimulus is quickly processed. Communication managers often stimulate affects in order to influence (in advertising, product placement and TV sponsorship where positive feelings are induced by the context of insertion). In this case, the individual consciously perceives a brand, and possibly also the associated message. However, he is neither aware of how the affective processes operate and influence his processing, nor that affectively charged stimuli get associated with a given brand in his memory. Influences caused by attitude conditioning, where psychological processing take into consideration two stimuli will be the third type of examined influence. Influences relating to emotional contexts and the effects of contrast-assimilation are a forth type of influence, where processing are much more sophisticated.

Non-conscious perceptions have effects on implicit attitudes
In everyday life, there are numerous examples where brands appear into the visual or auditory field of individuals, while they do not pay the slightest attention to any brand signs (a logotype or a name). Perception, memorization and influence, if any, are not conscious. This is the first type of non-conscious marketing communications influence. This happens mainly when an individual focuses on a certain area of a media support, while a brand is displayed next to his focus of attention: on an Internet image just below an advertising banner or on a football player during a TV football match, while a sponsorship banner is displayed in the background.

Several experiments of brands perceived outside the visual focus identified processes able to activate cognitive representations of an already memory-recorded brand, and also to pre-activate a network of brand-associated representations in memory [11]. Automatic processes are non-conscious activities that do not use attention and are inaccessible to subjective experience. They are involuntary (the will does not play any role in triggering them), quick and irrepressible processes (it is impossible to intentionally change their flow) [12]. In a non-conscious perception, such automatic activities would result in a better appreciation of the advertised brand [13-15]. Experiments conducted by Shapiro and co-workers [16,17] prove that the advertised brand is then promoted to a better position in the consideration set. Identical influences have also been identified in the non-conscious perception of radio broadcast commercials. Perfect and Edwards [18] showed that, after the automatic processing of auditory stimuli generated by radio advertising, the individuals' appreciation of advertisements was higher. It is worth noting that the effects of non-conscious perception were identified after experiments that used, on the one hand actual brands for which the individuals already had memory representations and, on the other hand new brands designed for the express purpose of research. In the latter case, exposure leads to the emergence of memory representations. Nonconscious perceptions produce implicit attitudes.

Certain experiments highlight the limitations of non-conscious perception effects. Vanhuele et al. [19] flashed an advertising banner fifteen times, associating a new brand to the picture of a product in the peripheral visual field, without the subjects being aware of the fact. They did not manage to memorize this association.

\section{Influences of low-level attention exposures: mere exposure and forgotten mere exposure produce implicit attitudes}

In certain types of exposure, the individual does not make any explicit judgment in the reception stage. First, this is the case of a quick sensorial contact, focused on the brand, which only communicates by showing its logotype. The second case is that of a receiver allocating so little attention to a commercial that he only perceives the logotype or the brand name very quickly, but not the advertising narrative. What is the influence of a single quick exposure to a logotype? While in social psychology there are countless researches showing that mere, short and repeated exposures to various types of signs suffice to have its representations stored in memory and appreciated [20,21], in marketing communication there is less research done. This is the second type of non-conscious marketing communications influence.

Studying the effects of a mere aural exposure to a brand, Holden and Vanhuele [22] showed that one day only after hearing, once, the name of a fictitious brand, when the contact is already forgotten, the subject is under the impression that the brand is a well-established one (like a "false fame effect"). Effects of mere visual exposure equally occur 
Citation: Courbet D, Fourquet-Courbet MP (2014) Non-conscious Effects of Marketing Communication and Implicit Attitude Change: State of Research and New Perspectives. Int J Journalism Mass Comm 1: 103. DOI: http://dx.doi.org/10.15344/2349-2635/2014/103

on the Internet where quick exposures to advertising leave memory traces on subjects who have already forgotten having seen the messages [23]. Very few studies focused on the persistence of such effects in memory. Positive attitude effects are still identifiable seven days after exposure: a) when subjects recall the exposure but do not remember exactly the brands they had been exposed to a week before [24]; b) when subjects recall neither the brands nor the exposure as such [25]. In an experiment conducted by Courbet et al. [5], subjects were exposed to either a textual or an iconic advertisement for a fictitious brand on the Internet. Pop-ups flash four times each, every time for three-seconds. The experiment studied the effects seven days and three months after exposure. The results show the overall positive effects of the pop-ups, the superiority of the image over words for effects on implicit attitude toward the brand and the purchase intentions. But the words produce more semantic effects than the image.

If such effects of mere exposure concern brands displayed in the forefront of commercials, they have also been identified in the case of brands advertised in the background of commercials. In a first stage, Nordhielm [26] repeatedly exposed subjects to an abstract image. In a second stage, this image was the background of a commercial displaying an unfamiliar product in the forefront. In this case, the effect of mere exposure to the background comes into play: without actually knowing why, subjects have a better attitude towards the unfamiliar product and a stronger wish to buy it.

To explain influences induced by the non-conscious perception of a brand on the one hand, and a mere exposure or a mere forgotten exposure on the other hand, researchers resort to cognitive psychology and cognitive social psychology models. Let us have the example of a new brand, unknown to the subject and that he sees for the first time in an advertisement that he treats quickly and superficially. The model explains that when the receiver has one or more quick sensorial contacts with a brand, representations of the logotype general structure, i.e. a rough sketch (or the approximate sound of the brand name) form automatically in memory, without his being aware of it. When, a couple of days later, the receiver comes again into contact with the brand, for example in the point of sale, he is neither able to recall the exposure context nor say he has already seen the brand in advertisements. Nonetheless, the infra-conscious perceptual system "recognizes" it and treats it much quicker. This would be an effect of perceptual fluency [27]. The structural representation stored in memory is then automatically activated in a matter of milliseconds, without the subject being aware of it. Once the brand representation activated, since processing in the first exposure stage have been very quick and superficial, the individual's memory cannot let him know where he has seen it before. The effect of strong perceptual fluency does not depend on the level of attention allocated upon exposure [28]: it is noticeable in divided- or full-attention receptions. The effect would even be amplified in the absence of focused attention [29]. It is present whatever the nature of the processing, either superficial or in-depth [30], in the presence or absence of emotions [31]. In studies using a brand known to the consumer, this brand is already represented in memory. If, during exposure to an advert, the brand appears in the peripheral visual field, it will pre-activate the structural representation of the brand and lower its activating threshold. With every new exposure, the perceptual fluency increases: the representations and the attitude become more accessible in memory.

According to Mandler's model [27], upon judgment or selection, perceptual fluency is spontaneously and automatically misattributed (falsely attributed), to cognitive and affective characteristics (attributes) of a brand [28]. A misattribution of perceptual fluency makes the consumer think for example that the brand is a high quality one. Since, as a general rule, individuals prefer familiar stimuli, Lee [32] explains that an unknown stimulus automatically generates a level of uncertainty in one's judgment: thus a new brand might cause some sort of "psychological discomfort" and be rather evaluated as negative. By increasing perceptual fluency, the brand repetition decreases the uncertainty, causes a positive feeling due to habit connotations and a certain familiarity, and would thus automatically raise the score of the brand affective evaluation.

Certain experimental results show that non-conscious or forgotten perception of a message associating a brand with a product may, under certain circumstances, associate in memory the brand with the product or make the brand join the consideration set $[33,34]$. Recently, researchers have explained these effects via the cognitive model of conceptual fluency [6]. Commercials linking a familiar brand (stimulus 1 ) to its product sector (stimulus 2) increase the accessibility of semantic networks associating the two stimuli in memory. Then, following a sensorial contact with one of the two stimuli activating its representation in memory, the other -automatically pre-activatedstimulus will be recovered more easily. Conceptual fluency translates the ease with which a brand comes to a consumer's mind when he is processing concepts or meanings he has associated with that brand in his memory. The more frequently a brand-with-product-sector association is seen in commercials, the better activated the conceptual association network is in the memory, the lower the activation threshold and the higher the brand accessibility in the memory semantic network associating the brand with its product sector [34].

Attitude accessibility, which indicates the attitude "strength" measured by the response time [35], is thus a type of past experience traces which are not identified via introspection and determines the implicit attitude [7]. In a marketing communication context, increasing attitudinal accessibility provides the brand with several benefits. According to Roskos-Ewoldsen and Fazio [36], the attitude towards a highly accessible brand would strongly direct the attention to the brand at the outlet on the one hand, and to all messages of the brand, on the other hand. By quickly labelling the stimuli in the message, a higher accessibility would also contribute to making the message processing easier [37].

Receivers of a message, who have a highly accessible positive attitude towards a source, are much easier to persuade by a message signed by the same source [38]. Favorable and highly accessible attitudes equally influence the interpretation of ambiguous data (e.g. an individual having trouble in assessing the qualities of a recently purchased brand) by biasing data processing in favor of the attitudinal object [39]. Finally, Berger and Mitchell [40] show that repeated advertising makes the attitude towards an object more accessible and consequently more predictive of further behaviors. Later on, we will examine the connections with behavior by showing that, under certain circumstances, attitudinal accessibility and implicit attitude allow prognoses and are major determining factors of some quickbuy or low-involvement product purchasing [41].

\section{Attitude conditioning produces effects on implicit attitudes}

Attitude conditioning is performed within an experiment protocol aimed at forming or changing attitudes by repeatedly associating two stimuli [42]:properties ofanaffectivelyor semanticallycharged stimulus (unconditional stimulus US, e.g. a pleasant piece of music) are 
Citation: Courbet D, Fourquet-Courbet MP (2014) Non-conscious Effects of Marketing Communication and Implicit Attitude Change: State of Research and New Perspectives. Int J Journalism Mass Comm 1: 103. DOI: http://dx.doi.org/10.15344/2349-2635/2014/103

transferred to an affectively or semantically neutral stimulus (a conditional stimulus CS, i.e. a brand). This is the third type of nonconscious marketing communications influence. Research focused more on the transfer of affective evaluations (evaluative conditioning) than on semantic transfer (or attribute transfer, non-evaluative conditioning). In advertising, the effects of attitude conditioning have been proven in different contexts. A product associated with a pleasant piece of music is evaluated higher than one associated with disagreeable music [43], The effects of evaluative conditioning are stronger in forming attitudes (the case of new brands) than in changing already established ones (the case of familiar brands) [44] In this latter case, some research studies did not manage to change attitudes [45], while others registered some small-scale changes [46]. If Stuart et al. [47] showed that a single association suffices to trigger conditioning; Pechman and Stewart [48] think that conditioning requires fewer repetitions of affective advertisements than rational ones. The most effective commercials would be those implementing a forward association conditioning (versus retrograde), i.e. those citing the brand first (CS), before recalling the associated positive attributes (US) [47]. Excepted Grossman and Till [49] who show that effects last for three weeks, new research should be undertaken into the high priority issue (in advertising) of making effects last.

Since research procedures are significantly different and results are often contradictory, debates focus on the role of awareness. If consensus has been reached on the fact that conditioning may occur while individuals are neither aware of the experiment objective (demand awareness), nor of memorization and influence method, three explanations have been advanced with respect to contingency awareness of the two stimuli in commercials. The models distinguish between attitude formation and change.

First, in the affective mediation model, the formation of attitude by attitude conditioning is underlain by affective processes only, which operate unwarily and non-cognitively. Evaluative conditioning takes place via direct and automatic affective transfer upon exposure that does not depend on the awareness of contingency between US and CS $[50,51]$. By checking the absence of awareness of the two stimuli contingency, Dempsey and Mitchell [52] show that implicit attitude with regard to a fictitious brand of pens, previously associated with positive images, is better than in the case of a pen associated with negative images. Further on, the conditioning of implicit attitudes seems to resist commercials that run contrary to the attitude concerned, provided such commercials are not processed in a highly sophisticated way. Walther [53] mentions the possibility of a nonconscious effect of attitude diffusion. This is a phenomenon where US affects the evaluation of CS (the brand), and also of other stimuli associated with a brand. For instance, within a brand extension strategy, a positive attitude towards a brand would diffuse into all the products marketed by that brand. The theoretical framework of implicit social cognition explains such affective transfers by an automatic formation of associations between representations in memory and by an automatic activation of associations [54,55]. A theoretical model is proposed where conditioned attitudes may determine behavior, if the latter is spontaneous and not based on a sophisticated attitude (MODE model, see below).

Secondly, in the cognitive mediation model, attitude conditioning cannot occur without awareness of the two stimuli association and without a minimal cognitive activity of the subjects [56]. If most researchers estimate that contingency awareness is a must in changing existing attitudes, others show that it is equally needed in order to a new attitude towards brands [57]. Meersmans et al. [58] explained that the cognitive mediation model was the best qualified to explain the transfer of attributes (or semantics) mainly emphasized in advertising by Kim et al. [59]. They associated the picture of a box of a fictitious pizza brand (conditional stimulus) with the picture of a racing car (nonconditional stimuli). Having been exposed to this association ten times, the subjects were then asked how long it would take this brand to make a pizza. The exposed subjects gave a shorter cooking time than the subjects in the control group. However, methodological procedures in this experiment do not allow eliminating the hypothesis whereby the transfer of the "speed" attribute of the racing car to the pizza brand occurred via a conscious cognitive process.

Thirdly, the double affective-cognitive mediation model postulates that conscious cognitive mediation and non-conscious affective mediation operate in parallel [60]. Formation of beliefs about a brand and the direct affective transfer of emotions to the brand would both occur in the case of attitude conditioning [59]. If more research is needed to better distinguish between these three models, attitude conditioning produces effects on implicit attitudes, in accord with Greenwald and Banaji [7].

\section{Emotional contexts have effects on implicit attitudes}

Whenever a consciously perceived brand is processed while the individual experiences positive emotions, non-conscious processes operate in parallel with conscious ones in the working memory. This is the fourth type of non-conscious marketing communications influence. Individuals ignore, on the one hand, how contexts and emotions act on their conscious processing, and on the other hand, the fact that contexts and emotions make them memorize specific brand representations. Researches on emotional context effects do not systematically measure the non-conscious nature of processes. Still, they are genuinely non-conscious processes and effects inasmuch as receivers are not able to verbalize them. If receivers are aware of the assimilation effect, for instance, as we will see later on, a contrast effect occurs.

Research dealing with the processing of advertising placed in emotion-generating contexts or programs distinguishes between valence effects and arousal effects. A positive emotional valence has a favorable impact on the attitude towards a brand: we are dealing with the assimilation effect [61]. Advertising in a funny or happy editorial or program context is better recalled and globally conducive to a more favorable attitude towards a message and a brand than one placed in a sad context $[62,63]$. Effects of positive valence have been identified as well under natural advertising circumstances, i.e. in media press [64] and television [65], as under TV experimental conditions [66]. In the particular case where a program causes temporary negative feelings (e.g. fear in a horror movie), Murry and Dacin [67] showed that the global appreciation of the program has a positive impact on the attitude towards the advertisements inserted therein.

Research into the emotional arousal impact on the processing of advertising has been conducted from two different theoretical perspectives. The first one explains that arousal interacts with valence. Arousal moderates the effect of valence, with higher levels of arousal heightening mood valence effects [66]. The second perspective maintains that arousal acts independently of valence. However, results are contradictory. Some research shows that when amusing the subjects, the arousal reduces the effects 
Citation: Courbet D, Fourquet-Courbet MP (2014) Non-conscious Effects of Marketing Communication and Implicit Attitude Change: State of Research and New Perspectives. Int J Journalism Mass Comm 1: 103. DOI: http://dx.doi.org/10.15344/2349-2635/2014/103

because it prevents them from paying attention to subsequent advertising [68-71]. Other research reveals the favorable attitudinal effects of arousal [65]. Future research is therefore required to provide a better insight into the non-conscious effects of arousal by focusing on the role of moderating variables such as the degree of involvement in the program or the congruency between the program and the commercial content [72].

While studying the impact of TV broadcast sponsorship, Courbet [73] removed all possible memories of the exposure stage when applying the questionnaire in order to record the effects of emotional contexts on the subjects' judgments of sponsors. The program context surrounding the appearance of a new brand impacts on the attitude towards the brand for a week after exposure, while subjects have completely forgotten having seen the brand. In line with the assimilation model, results revealed that a brand is better appreciated when sponsoring a happy program than a sad one.

In connection with product placement in movies, Russell [74] proposes a theoretical model focused on congruency: a brand will be appreciated more if placed in a happy program, and this holds true even if later on, the individual cannot remember the exposure context. By integrating variables specific to product placement, some research used implicit measures to lower the probability of the receiver's ability to remember and be aware of the exposure and insertion context. Exposure to a movie where a brand not explicitly memorized (i.e. unrecognized in a post-experiment questionnaire) is placed strengthens the choice intention for that brand [75] and improves the attitude towards the brand [76]. Russell's [77] shows that memory improves when modality and plot connection are incongruent but persuasion is enhanced by congruency. While congruous placements appear natural, incongruent placements adversely affect brand attitudes because they seem out of place and are discounted. Subjects did not consciously recognize the lower plot visual stimuli even though their attitudes where positively affected. For Yang et al. [78], a product placement leads to forming an implicit attitude towards new products, without however having enough power to change already formed attitudes towards existing products. In this case, a product placement might only reinforce the accessibility of an existing attitude.

What are the affective and cognitive processes underlying the assimilation effects and the emotions' effects on the brand processing? Positive moods may impact, and interact, at five levels, on processing antecedents, on processing themselves, on processing consequences and also on the recovery.

First, positive moods may cause irrelevant thoughts (having no connection with the task) which consume resources and reduce the available capabilities [79]. In general, the higher the positive arousal, the more limited the capabilities of the working memory [80]. Secondly, positive moods lower the motivation to allocate resources and consequently to strongly process [81]. Better scores of explicit memorization of advertising are obtained with a moderate positive arousal [82]. Indeed, whenever a program causes a high level of positive arousal, there is less attention given to advertising, memorization and purchase intention $[69,83]$.

Thirdly, positive moods directly and automatically influence the nature of processing and the type of strategies applied. Positive moods activate automatic and faster processes, which the subject can not control and are independent of motivations [84]. Indeed, a positive affect acts like an indicator signaling to the body that all is well in the immediate vicinity [85]. Consequently, the individual may become more "open" and willing to process environment data of less importance and consequence to him, such as commercials $[66,86]$. This model explains the results that Shapiro et al. [71] obtained, i.e. the arousal and valence dimensions of mood differentially affect ad processing, with arousal affecting the level of processing and valence influencing the nature of processing. The processing level was shallower when the arousal level was high rather than moderate. Positive valence was associated with the greater use of schematic processing, whereas negative valence was associated with the greater use of data-driven processing.

In a different model, Schwarz and Clore [87] (the affect-asinformation model, 1988) explain that in this context, the individual would not elaborate on the message but would simply ask himself "How do I feel about it?" By this heuristic, he could unwarily and "falsely" allocate the positive mood stirred up by the insertion context to the brand message, which he would then judge as positive.

In the fourth place, positive moods interfere with the way messages are treated upon reception. Forgas and Bower [88] propose a model whereby a major part of the information on social objects stored in the semantic memory is associated with affective valences. Thus, positive emotions automatically activate, in the long-term memory, the material of positive affective valence. Forgas [89] explains that in carrying out a social judgment, the experienced feelings are subject to emotional infusion (affect infusion model, AIM). This is a process whereby affective information influences cognitive processes while getting incorporated into them, thus affecting learning, memory, attention and the associative processes, and leading to congruency effects [89]. The receiver who experiences positive emotions allocates closer attention to congruent information, i.e. to funny advertisements or to positively charged elements in an advertisement. In addition, positive emotions determine a biased processing. Without being aware of it, receivers feeling positive emotions look "on the bright side of things" [90] and they will be most likely to judge both the message and the brand more favorably than consumers in a bad or neutral mood will.

The fifth remark refers to Isen's [90]and Forgas and Bower's [88] models which explain that upon a recall, for instance at the outlet, the recovery of brand representations, whose advertising had been processed in a positive mood, will be automatically facilitated if the individual is again in a good mood (dependency effect) [86].

The assimilation effect is inhibited when the receiver realizes that it is the emotionally positive context that makes him appreciate the brand more. Indeed, an attitude-corrective stage towards the brand may intervene if the consumer believes having been influenced unwarily [91]. Two closely related models explain that, under certain circumstances, individuals resort to an excessive correction of their judgment, which may then come to contradict the initial one, the assimilation-contrast model [61] and the set-reset model [92]. The latter authors designed brand advertisements using voice off of appreciated and unappreciated celebrities. They wanted to find out how individuals evaluated the brand when they recognized or did not recognize the celebrity. In the absence of recognition, an implicit assimilation effect is identified ("the set effect"). Those who recognized or did not recognize the celebrity. In the absence of recognition, an implicit assimilation effect is identified ("the set effect"). Those who recognized the celebrity set up a contrast effect. When subjects 
Citation: Courbet D, Fourquet-Courbet MP (2014) Non-conscious Effects of Marketing Communication and Implicit Attitude Change: State of Research and New Perspectives. Int J Journalism Mass Comm 1: 103. DOI: http://dx.doi.org/10.15344/2349-2635/2014/103

identified a celebrity they do not appreciate, the exposure to advertising improved their attitude towards the brand, since an overcorrection of the celebrity's influence ("the reset effect") occurred.

\section{Discussion and New Research Perspectives}

As shown above, the determinants and various processes, unidentifiable through introspection, but causing the storage of memory traces relating to a brand after exposure to marketing communication are many: formation of structural representations of a brand in memory, formation of networks associating a brand representation with affects or semantic concepts, increase of perceptual and conceptual fluencies, lowering the network activation threshold in relation with the brand. In agreement with the implicit attitude as defined by Greenwald and Banaji [7], these traces affectively polarize and mediate thoughts, feelings and judgments about brands. While discussing the contributions and limitations of major methodologies and measures of dependent variables, we highlight new perspectives of research likely to further the progress of research. We open up new perspectives first to increase the ecological and theoretical validity of methodologies; secondly, to improve the theoretical validity of dependent variable measure. A third research perspective, of a more theoretical nature, endeavors to better understand the links between implicit and explicit attitudes (and measures) on the one hand, and behavior on the other hand.

\section{Enhancing the ecological and theoretical validity of methodologies}

The diversity of non-conscious influences in marketing communication does not allow reference to a single definition or theory of awareness and unawareness. We should distinguish more clearly between the types of non-conscious processes on the one hand, and base each research methodology tackling such processes on specific theories, on the other hand. We propose new perspectives of research in order to increase the ecological and theoretical validity of methodologies focusing on non-conscious perception, non-conscious message processing and non-conscious memorization. Whatever the processes under consideration, one of the first validity requirements is to ensure the unawareness of the experiment objectives and demands. We will review different tests that vary according with the type of research.

\section{Methodologies tackling non-conscious perception}

The threshold model devised by Cheesman and Merikle [9] is relevant to research on the non-conscious perception of a brand and its message as far as it proposes a definition of awareness and unawareness. This model distinguishes between two types of thresholds: objective and subjective. A stimulus exceeds the objective threshold when it stimulates the sensorial system and causes a psycho-physiological response of the body. The subjective threshold is exceeded when an individual, focusing his attention, is able to verbally report the presence of a stimulus. In this situation, awareness is defined as the capacity of a given subject to intentionally produce a symbolic response, i.e. verbal response discriminating information. If the objective threshold is not reached, no perception occurs. Subliminal perception exceeds the objective threshold, but not the subjective one: no conscious detection is possible, even if the individual's attention is focused [8]. When the subjective threshold is reached, there is conscious perception. Two things should be noted here. First, there is no absolute threshold but individual ones, varying according with individuals, their motivation at a given time, as well as with the reception circumstances. Secondly, there are only two possibilities: either the subject is aware or he is unaware of his perception.

The application of the threshold model makes us realize how numerous situations involving non-conscious or subliminal perception are in marketing communication. We will discuss three cases. In the first one, commercial-originated sensorial information is by far too limited for an individual, even if closely focused, to identify a brand. This happens when the sound of a message is too low or when a banner is too far away to see. Experimental research studied the effects of exposures flashing stimuli (for 5 to 40 milliseconds, according to research) in the central visual field [93]. The results highlighted attitudinal and behavioral effects of stimuli, situated between the objective and the subjective thresholds, provided the stimuli humored a pre-existing motivation of the individual. While these results are interesting for fundamental research, their ecological validity in a marketing communication context should be further refined to bring experimental exposures closer to the conditions of everyday-life exposure. The second case deals with stimuli emerging in the peripheral visual field. The peripheral field is situated at a 2-degree angle off the visual fixation point, and it includes the parafoveal field located between 2 and 6 degrees off the visual fixation point. We will explain later on that some studies identified effects after exposures to the brand in the peripheral field. In the third case, the brand is advertised in the auditory field (radio broadcasting) or in the central visual field, but the receiver pays no attention to it. This happens when a viewer faces the TV set while thinking of something else and not watching the commercials on the screen, or when an individual talk with somebody else while a commercial is being broadcast by a radio station. In order to become conscious, a brand perception does not require, as it did in the previous instance, the subject's psychomotor effort (direct his sight), but only depends on his allocation of attention. In psychology, research on the dichotic listening task which requires subjects to monitor information presented to one ear while ignoring information presented simultaneously to the other ear, showed that automatic processing come into play in the absence of attention [94]. Although a frequent situation, its effects remain insufficiently explored in a marketing communication context.

From a methodological perspective, the validity of research on these three cases is closely dependent of the validity of the non-conscious perception control. The literature mentions various procedures meant to create a non-conscious perception framework, from simple procedures to rather sophisticated devices. A simple procedure consists in instructing the subjects to read and then discuss press articles in the proximity of which there are commercials whose impact is to be examined, but which the subjects are not supposed to read. According to Krishnan and Chakravarti [95], such instructions would suffice to set up a framework where the exposure to the commercials is incidental. Shapiro et al. [16] devised a more sophisticated procedure, i.e. they set up a subliminal perception context where the commercials appear in the peripheral vision: the Attentional Resources Tracking (ART) method. A text scrolls at a certain pace in the central section of a computer screen. The subject is asked to read it carefully and understand it, while following the words with the cursor. While he concentrates on the text, advertisements appear in the peripheral vision field, to the right or left side of the text. However, the subject should not consciously perceive them. If he watches them, the time allocated to reading the text and which is measured by the computer 
Citation: Courbet D, Fourquet-Courbet MP (2014) Non-conscious Effects of Marketing Communication and Implicit Attitude Change: State of Research and New Perspectives. Int J Journalism Mass Comm 1: 103. DOI: http://dx.doi.org/10.15344/2349-2635/2014/103

will increase slightly. This method shows that commercials not watched in the central visual field are still processed and have an influence on the attitude towards a brand. Even if these two methods are flexible and propose exposure circumstances closer to everyday life, they set up a not-so-strict measure of the non-conscious nature of perception. Undoubtedly, the ART method detects the subjects whose eyes leave the text to spend some time on the commercial; it might however find it more difficult to detect those subjects who do a sequence of eyemovements in order to see the brand on the commercial.

A methodological framework aimed at a rigorous study of nonconscious perception should allow to first dissociate between conscious and non-conscious processing to then target only the non-conscious ones [96]. It might be advisable to adopt a four-step procedure. The first step should aim to specify, with accuracy and in a clear theoretical context, the conscious versus the non-conscious processing, in order to identify a theoretically-valid measure of what is conscious (e.g. it is conscious what may be verbalized). In a second step, this measure should be clearly proven to show that the considered stimulus is below the subjective threshold and therefore not consciously perceived. In a third step, with the previously described framework in place, it should be shown, by resorting to a second measure (e.g. the dependent variables measure), that effects are noticed and that they occur beyond any awareness. Finally, the fourth step should conduct a thorough investigation of the roles and effects of non-conscious processing, in relation to relevant variables and according to an experimental design, with or without a control group.

As individuals have different perception thresholds, it is recommendable to make sure, by verbal questioning, that the subject is unable to identify the stimulus that must be below the subjective threshold. To study non-conscious perception in the peripheral visual (Table 1) field, a double check is often mandatory, even if rarely done in research. Recording eye movements by camera (eye-tracking) will check the angle of the stimulus to the visual fixation point [19] Moreover, as sometimes we can identify a stimulus in the peripheral field, a verbal test performed, whenever possible, upon the very appearance of the stimulus [97], or failing that, as soon as possible after exposure; will make sure that conscious perception is absent. According to Holender [97], it is appropriate, depending on the experiment objectives, to remove from the experiment the subjects able to either report the presence of a stimulus, or to specify one of its genuine features.

\section{Methodologies tackling unconscious processing and memorization}

An individual may be aware of perceiving a brand, possibly also the commercial, in full or in part; however, he cannot be aware of the automatic processes and memorization that sometimes operate in parallel with certain conscious processing of the message. The cognitive psychology literature dealing with this type of reception discusses two concepts of the unconscious, on the basis of which we can develop two types of methodologies in a marketing communication context: a strict method and a flexible one. The flexible method uses two criteria to determine the absence of awareness in memorizing. First, the nonintentional, i.e. incidental, nature of memorization upon exposure: the receiver does not explicitly intend to learn and memorize information related to a brand. The experiment procedure and instructions must prevent intentional memorization. Secondly, when measuring

\section{Refer to awareness definition and the two thresholds of} Cheesman and Merikle [10].

2. Rigorously check the non-conscious nature by adopting up a four-step procedure:

2.1 Conceptually dissociate conscious from non-conscious processing through an operational measure of unawareness.

2.2 Use by this measure to show that the considered stimulus is below the subjective threshold.

2.3 Highlight the presence of non-conscious processing and effects via a second measure (dependent variables measure).

2.4 Study non-conscious processing and effects according to an experimental design.

\section{Associate a set of unawareness control criteria:}

3.1 Control via direct measures, whenever possible: verbalization and/or psycho-sensorial techniques (e.g. eye-tracking).

3.2 Control via post-hoc verbal measures as soon as possible after exposure, in order to check:

a) the absence of experiment-demand awareness;

b) the absence of perception awareness, either by means of a post-experiment recall questionnaire while giving progressive cues, or if possible, by testing subliminal stimulus recognition. 3.3 Do check-ups for each subject in view of inter-subject variability.

4. Conduct research specific to marketing communication and closer to everyday life conditions, on:

4.1 Visual or auditory perception of a brand appearing in the central section of the sensorial field, though non-detectable in focused-attention mode (e.g. distant vision of a brand).

4.2 Non-conscious processing and effects of a brand displayed in the peripheral visual field.

4.3 Non-conscious processing and effects of a brand explicitly present in the auditory field (radio in dichotic listening) or in the central visual field, though non-perceived through lack of attention.

Table 1: Recommendations to enhance the theoretical and ecological validity of methodologies tackling non-conscious perception in marketing communication

the memory effects, the researcher should apply post-experiment questions to make sure that the subject is unable to report, verbally and correctly, the memorized traces under study and which are supposed non-conscious [98]. According to the flexible method, tests checking the non-conscious nature of memorization are usually applied after the recovery, judgment or decision-making stage with respect to a brand. In the case of research into the persistence of effects, it can be done several days after the exposure.

In the strict method [97], there are additional criteria to the previously mentioned two. In attitude conditioning for example, this means that the individual must be unable to verbalize, on the spot, the genuine psychological processes leading to memorization. During exposure, it is possible that the subject becomes aware of the brand-stimulus contingence, but forgets it immediately. Stricto senso, contingency effects are no longer non-conscious. The test should be performed upon exposure, by asking the subject to verbalize then and there. On the other hand, the strict method requires certain tests that are not always doable form a procedural point of view, as they would artificially draw the subject's attention to aspects which would normally have escaped him. They should therefore be performed as soon as possible. This method equally supposes that subjects should not only be asked general postexperiment questions relating to the actual objectives of the experiment, as Allen and Janiszewski [99] did, but also that 1) their 
Citation: Courbet D, Fourquet-Courbet MP (2014) Non-conscious Effects of Marketing Communication and Implicit Attitude Change: State of Research and New Perspectives. Int J Journalism Mass Comm 1: 103. DOI: http://dx.doi.org/10.15344/2349-2635/2014/103

Page 8 of 14

awareness of the researcher's demand; 2) their awareness of stimuli association [57] be separately tested. A technique consists in giving them progressive cues. Individuals are asked to give honest answers to questions relating to their awareness of the experiment purpose and of the stimuli association, via general questions first (for instance "summarize below what you believe was the purpose of the study?"), to then gradually move to more specific ones ("have you noticed if the brand displayed a particular feature?"). Whenever possible, recognition tests should be preferred to recall tests: the subject is asked if he is able to identify, within a displayed set, the associated stimuli. Subjects are then divided into different groups according to their awareness capability.

In order to improve the theoretical validity of memorization unawareness tests, Tulving's theory [98] should be definitely be taken into account. This theory devises a way of distinguishing between items coming under the scope of awareness and of unawareness, by associating autonoetic awareness with autobiographical memory, and noetic awareness with semantic memory. First, autonoetic awareness is linked to the recalling ability by mentally traveling in time in order to relive a memory within its context, i.e. to relive the experience together with the thoughts, feelings and perceptions experienced when "acquiring" the event. An individual does or does not have the capacity to recall, i.e. does or does not have autonoetic awareness. If he has noetic awareness, its level can be more or less high and is distributed along a continuum ranging from a mere impression of familiarity (of "déjà vu", indicative of very weak autonoetic awareness) measurable via recognition or indirect tests [100], to very rich memories indicating very strong autonoetic awareness measurable by explicit recall tests.

Secondly, noetic awareness means being aware of knowing things about the world [101]. For example, an individual is able to explicitly give the true reasons underlying his cognitive or affective judgments about a brand, by actually specifying the attributes stored in his memory as a consequence of direct experience (his own) or indirect experience (from advertising or friends) of the brand. An individual does or does not have noetic awareness [102]. If he does, it is distributed along a continuum ranging from a mere impression of familiarity linked with conceptual fluency, measurable via recognition or indirect tests, to a high capacity to correctly allocate the grounds of his judgments, and to explain knowledge-related-attributes (measurable by explicit recall tests).

On the basis of Tulving's [98] theory, Vanhuele et al. [19] devised very strict criteria meant to check the non-conscious nature of processing. They study the effects of non-conscious perception, processing and memorization of banners advertised on the Internet, which include fictitious brands flashing in peripheral vision. While the subjects are reading a text, banners flash above it, in the peripheral visual field. During exposure, the visual attention is directly measured by a camera (eye-tracking): as soon as the subject initiates a sequence of eye-movements posing a risk of brand-perception, an IT application makes the banner vanish and replaces it with a filler banner. Besides this psycho-sensorial criterion used to check the lack of attention focused on the commercial, a second criterion is applied to measure the absence of autonoetic awareness: immediately after recording the subjects' answers about the brands on the banners, the researchers make sure that subjects assert they have never seen those new brands before. The technique adopted consists in giving them increasingly accurate information to help them remember. Even in the presence of strong cues, subjects were not able to recall the spatial and temporal context of exposure. By asking subjects to explain their answers, a third control comes into play and establishes the absence of noetic awareness, by making sure that, when giving an answer, the subjects do not know the actual reasons (i.e. experimental exposure) which underlie their judgments of brands.

When experiments use fictitious brands, it is often difficult to define a measure of awareness on the basis of a measurement of brand recognition. For instance, exposure in non-conscious peripheral vision to a new brand may trigger automatic processing in the Perceptual Representation System [98], which stores the structural representation of a stimulus. When the test is applied and the memory is recovered, the PRS system generates perceptive fluency able to automatically give subjects the impression of having already seen the brand, while they do not necessarily have noetic or autonoetic awareness. Research into the temporal effects of mere exposures to new brands, perceived but forgotten [24,25] defines non-conscious effects by reference to autonoetic awareness linked to exposure. The absence of memory is checked by means of a post-experiment questionnaire or interview able to show that the individual is unable to recall, even in the presence of extremely helpful cues, the spatial and temporal context of exposure on the one hand, and the processing taking place during exposure on the other hand.

The research on the non-conscious effects related to emotional infusion by means of fictitious brands [73] often attempts to work out a frame defining the absence of autonoetic and noetic awareness in connection with exposure. At various levels of noetic awareness of exposure, measured by the memory recall technique, an individual is able to correctly explain the reasons underlying his judgment, saying, for instance, that the brand is high quality a) because he knows it is advertised (low noetic awareness, only recalling a generic exposure context); b) because it is advertised on television (moderate noetic awareness); c) because it was advertised on television, in a given commercial, surrounded by a given emotional context (strong noetic awareness that might produce a contrast effect). Thus, in the framework of experiments using fictitious brands, the individual who makes a judgment on the brand quality but is not able to state the explicit grounds of his judgment on data effectively appearing within the exposure context lacks noetic awareness (Table 2). It is then highly probable that he calls upon his implicit memory, and builds his judgment on conceptual fluency or on affective traces generated by emotional infusion.

\section{Improving the theoretical validity of dependent variables measures}

In recent years, research into the non-conscious influences of marketing communication have progressed due to the use of implicit measures in recording dependent variables [103-105]. Define implicit measures as "measurement methods that [106] (a) avoid requiring introspective access, (b) decrease the mental checking available to produce the response, (c) reduce the role of conscious intention, and (d) reduce the role of self-reflective, deliberative processes." Subjects are unaware of what is being measured, unaware of how it is being measured, or unable to control their performance on the measure. We will start with a presentation of the main types of implicit measures developed by psychologists and used in a marketing communication context, then propose a couple of research perspectives able to improve their theoretical validity. 
Citation: Courbet D, Fourquet-Courbet MP (2014) Non-conscious Effects of Marketing Communication and Implicit Attitude Change: State of Research and New Perspectives. Int J Journalism Mass Comm 1: 103. DOI: http://dx.doi.org/10.15344/2349-2635/2014/103

Page 9 of 14

1. Refer to Tulving [98] concepts of autonoetic and noetic awareness and unawareness.

2. Select either a flexible or a strict approach of unawareness in memorization (and processing) depending on experiment targets.

3. Rigorously control unawareness by associating a number of criteria:

3.1 For the flexible approach:

a) Set up a non-intentional memorization framework and check the absence of explicit incentives to supposedly non-conscious processing via specific experiment procedures and instructions; b) Check demand unawareness via a post-experiment recall questionnaire giving progressive cues;

c) Check the incapacity of verbally and accurately reporting processing and memory traces supposed non-conscious, via a post-experiment recall questionnaire including general questions(s);

3.2 For a strict approach, add the following criteria to the abovementioned a), b) and c):

d) Check, if possible directly, the non-conscious nature of processes via verbalization and/or psycho-sensorial techniques during exposure;

e) Check the incapacity of verbally and accurately reporting processing and memory traces supposed non-conscious, via a post-experiment recall questionnaire giving progressive cues;

f) whenever possible, apply a post-experiment recognition test.

4. Conduct research specific to marketing communication under conditions closer to everyday life on:

4.1 Exposures to forgotten messages and their temporal effects, by checking autonoetic unawareness via a post-experiment recall questionnaire.

4.2 Non-conscious effects of emotional contexts, by measuring autonoetic and noetic unawareness via recall tests and specify the different levels of noetic awareness.

Table 2: Recommendations to enhance the theoretical and ecological validity of methodologies tackling non-conscious memorization (and processing) in marketing communication

\section{From mere implicit measures to more sophisticated ones}

Whilst in recent implicit measures the analysis of the response time to questions is computer-assisted, previous generation measures were mainly based on comparisons between the relative sensitiveness of direct versus indirect verbal measures (an indirect measure does not concern what subjects believe). Using a first generation method, Kunst-Wilson and Zajonc [107] showed that, when first exposing subjects to a subliminal stimulus, and then to the same - this time explicit - stimulus in association with a previously unseen stimulus, the psychism only reacts to the subliminal stimulus when the subject is asked indirect questions. When asked which stimulus they have previously exposed to (direct recognition test), the subjects will not recognize it. When asked which of the two stimuli they prefer (leading indirect test), they will pick the one subliminally perceived before. This serves to establish the presence of a non-conscious process and shows that an indirect measure is more sensitive than a direct one (wherefrom the conscious or non-conscious nature of the process is inferred, in our case recognition) for the same perceptual discrimination between two stimuli.

A second type of first generation method is the Process Dissociation Framework, which compares direct and indirect measures [108].
This method was applied to marketing by Holden and Vanhuele [22] and Shapiro and Krishnan [24]. According to Jacoby [108], a memory test does not engage a single recovery process, since automatic and controlled processes often operate in combination. The method is designed to separate, within the same task, the controlled processes (such as the conscious memory of an advertisement, originating in the explicit memory) from the automatic processes (such as the impression of familiarity with the brand, originating in the implicit memory). The dissociation framework combines, on the one hand, the results of an experimental situation where automatic and controlled processes operate in opposition, with the results of an experimental situation where both processes operate at the same time. Shapiro and Krishnan [24] showed that exposure to a brand in divided-attention mode does not impact on the impression of familiarity with a brand (due to an automatic recovery process in the implicit memory) recorded one week later, but has a negative impact on the explicit recall of a brand. However, Jacoby's framework, inasmuch as it has been applied, makes it possible to only study the memory effects of brand names in isolation, and not in association with other cognitive or affective representations. Last generation implicit measures allow the study of such memory associations.

A first type of last-generation implicit measures is priming [109]. Priming occurs when exposure to a stimulus influences how subject subsequently respond to the same or another stimulus. In long-term memory, priming refers to the activation of one concept by another. Using a technique derived from Dovidio's task of category inclusion [110], one week after the exposure, Courbet [25] asked subjects who did not remember having been exposed to fictitious brands to say, as quickly as possible, if the brands displayed had certain attributes (e.g. top of the range). The examination of response latencies makes it possible to infer the existence and the strength of the link, in memory, between the brands and the "top of the range" attribute. This implicit measure highlights the effects of exposure on brand judgments, while insufficiently sensitive explicit measures do not reveal any such effects. Priming techniques, still not enough used in marketing communication research, open up new perspectives in the study of cognitive and affective traces memorized after exposure to messages. It could be noticed that, when the memory representation of a brand only relates to the structural level, implicit measures identify the presence of perceptual fluency, provided that the brand is introduced to the subject through the same sensory modalities as in the previous exposure: if the exposure to a new brand used sound (radio advertisement), then it is a sound test that will show the effects of perceptual fluency [111]. Sensory constancy in introducing a stimulus is less essential if the fluency occurs at the conceptual level [112].

A second last-generation measure is the Implicit Association Test $[113,6]$. The computer-guided test requires that subjects pair two previously known concepts (for example "brand X" and "pleasant", or "brand X" and "unpleasant"). The more closely associated the two concepts are, the easier it is to respond to them as a single unit. So, if "brand X" and "pleasant" are strongly associated, it should be easier to respond faster when you are asked to give the same response to these two. If "brand X" and "pleasant" are not so strongly associated, it should be harder to respond fast when they are paired. The IAT gives a measure of how strongly associated the two types of concepts are. The more associated, the more rapidly you should be able to respond. Recently, Karpinski and Steinman [114] have proposed the single category implicit association test as a measure of implicit social cognition. The combination with a classical 
Citation: Courbet D, Fourquet-Courbet MP (2014) Non-conscious Effects of Marketing Communication and Implicit Attitude Change: State of Research and New Perspectives. Int J Journalism Mass Comm 1: 103. DOI: http://dx.doi.org/10.15344/2349-2635/2014/103

attitude scale gives two types of measures for the same subject: an implicit attitude measure and an explicit attitude one. Trendel and Warlop [115] showed, by means of IAT that in the absence of social desirability bias, sponsorship in tennis may prove as efficient with cigarettes brands (type of product perceived as inadequate to tennis) as with camera brands (type of product perceived as adequate to tennis).

\section{Improving the theoretical validity of implicit measures}

Debates on the theoretical validity of IAT and more generally of implicit measures oppose two theories [105]. The theoretical debates are based on the examination of links between implicit and explicit measures, but these approaches give contradictory results.

The first theory explains that implicit and explicit measures of attitude quantify the same psychological construct. The implicit measure provided by IAT reduces the measure error by attenuating, even suppressing, and the effects of context-induced response changes, of subjects' intentional faking and of demand awareness, which interfere with the construct measure when using explicit measures. When the consumer's involvement with a product is weak [116] or when judgments do not draw on strategies relating to the respondent's social image $[117,6]$, results show a strong correlation between implicit and explicit measures. Implicit measures of attitude would not therefore be contaminated by errors induced by the measure instrument. However, recent research has shown that it would be possible, under certain conditions, that subjects set up response strategies to IAT which change implicit scores [118] on the one hand, and that implicit measures get contaminated by context effects, for example by affect transfers, on the other hand [119].

The second theory explains that implicit measures quantify a construct other than the one dealt with by explicit measures $[120,121]$ (Table 3). Thus, IAT can measure two independent constructs in memory, i.e. implicit and explicit attitude. These two types of attitude may sometimes be identical, and sometimes different. Wilson, Lindsey and Shooler [121] explain that persuasive communication modifies explicit attitudes much easier than implicit ones.

Even if literature in psychology [106] contributes to a better understanding of IAT psychometric qualities, more ample research is needed to segregate one theory from the other and better explain the role of context factors in implicit measures. The stakes are high for both theorists and practitioners of marketing communication, since most of efficiency measures and effects used at present are explicit ones. Such measures risk underestimating the effects of commercials, of communication campaigns and advertising.

\section{A better insight into the links between attitudes (implicit and explicit) and behavior}

\section{Adjusting the MODE model [40] to marketing communication}

In marketing communication, the concept of attitude is mainly useful because it allows behavior prediction. Within an implicit social cognition context, the best known model linking attitude to behavior is the double process model (MODE), literally Motivation and Opportunity act as DEterminants of spontaneous versus deliberative attitude-to-behavior processes [123]. According to this model, attitude influences behavior via two types of processes operating either individually or in interaction. The first

\begin{tabular}{|c|c|}
\hline $\begin{array}{l}\text { Propositions to enhance the } \\
\text { theoretical validity of implicit } \\
\text { measures }\end{array}$ & $\begin{array}{l}\text { Implicit measures most } \\
\text { frequently used in } \\
\text { marketing communication }\end{array}$ \\
\hline $\begin{array}{l}\text { Implicit measures are } \\
\text { measurement methods that } \\
\text { (a) Avoid requiring } \\
\text { introspective access, } \\
\text { (b) Decrease the mental } \\
\text { control available to produce the } \\
\text { response, } \\
\text { (c) Reduce the role of conscious } \\
\text { intention, } \\
\text { (d) Reduce the role of } \\
\text { self-reflective, deliberative } \\
\text { processes. } \\
\text { First-generation measures } \\
\text { (non-computerized) } \\
\text { - indirect test [107] } \\
\text { - Process Dissociation } \\
\text { Framework [108] } \\
\text { Second-generation measures } \\
\text { (computerized) } \\
\text { - Priming [104] } \\
\text { - Implicit Association Test [122] } \\
\text { and Single Category IAT [116] }\end{array}$ & $\begin{array}{l}\text { 1. Better understanding } \\
\text { measured constructs by } \\
\text { studying the links between } \\
\text { explicit and implicit } \\
\text { measures. } \\
\text { 2. Better understanding } \\
\text { error of measurement } \\
\text { thanks to implicit measures: } \\
\text { do they suppress context } \\
\text { effects, intentional faking, } \\
\text { demand awareness and social } \\
\text { desirability? }\end{array}$ \\
\hline
\end{tabular}

Table 3: Main implicit measures in marketing communication and propositions to enhance their theoretical validity

process is called "spontaneous" because it relies on a non-conscious automatic activation of pre-existing implicit and explicit attitudes. In the case of spontaneous processing, pre-existing attitudes can influence individuals' perceptions, on one hand, and have a direct impact on their behavior on the other hand, with no conscious reasoning on their part. If the attitude with about a product is very accessible in memory, it can be automatically activated whenever the individual gets into contact with the product. In the case of a quick purchase and positive attitude, the product attraction will be higher. This is the case of most current consumer purchase. In this context, Fazio et al. [124] showed that attitude accessibility with respect to a low-involvement product is a variable that predicts behavior.

The second process is called "deliberative" and requires a certain motivation and capability to allocate attentional and cognitive resources to a detailed processing. The context must offer the subject with the opportunity (e.g. the time) to undertake such a processing. In a consumption context, this happens with highly-involving behaviors and important purchases. The evaluation of both the brand and the product would determine the behavioral intention and the behavior itself. In this case too, attitude accessibility predicts future behavior [125].

Even if the authors of the MODE model explain that in most social behaviors, spontaneous and deliberative processes are mixed up, the three types of models detailing the links between implicit and explicit attitudes on one hand, and behavior on the other hand are quite contradictory and do not directly concern marketing communication [126]. With respect to the first type, of the additive models, the two types of attitudes explain different segments of behavior variance. In one of the first research conducted in a marketing communication context, Maison et al. [116] showed that even when there is a positive correlation between implicit and explicit measures, each of them has an independent contribution 
Citation: Courbet D, Fourquet-Courbet MP (2014) Non-conscious Effects of Marketing Communication and Implicit Attitude Change: State of Research and New Perspectives. Int J Journalism Mass Comm 1: 103. DOI: http://dx.doi.org/10.15344/2349-2635/2014/103

Page 11 of 14

to a similar consumption behavior. As to the second type, of the interaction models, implicit and explicit attitudes interact in influencing behavior [126], study 1). Finally, for the third type, i.e. the double dissociation models, implicit attitudes predict spontaneous behaviors while explicit attitudes predict deliberative behaviors [126], study 2; [127]. In a marketing context, Friese et al. [128] show that people, whose explicit and implicit preferences regarding generic food products and well-known food brands were incongruent, were more likely to choose the implicitly preferred brand over the explicitly preferred one when choices were made under time pressure.

\section{Three new research perspectives on attitude-to-behavior links}

In future, it would be convenient to open up three perspectives of research specific to marketing communication, in order to improve models linking psychological constructs measured by implicit and explicit techniques to consumption behaviors. First, as it is likely that the three previous types of models explain different types of behavior, new research should be considered in order to differentiate amongst consumption behaviors on the basis of a taxonomy that does not only rely on a "spontaneous-to-deliberative behaviors" continuum. Indeed, in view of perceptual and conceptual fluency effects, it would be relevant to introduce contextual variables to discriminate between purchase behaviors where a previouslyexposed individual has or does not have visual access to the brand when making his choice. Such a difference would provide a better understanding of the roles and consequences of fluencies in the purchase process .

Secondly, it would be useful to examine memory recovery circumstances while distinguishing between noetic and autonoetic unawareness. Then, non-conscious psychological processes and effects should be further investigated through the examination of the roles of factors specific to advertising, like humor or music, in purchase behavior (Table 4)

1. Apply MODE model [41] by refining "deliberative versus spontaneous" typology while introducing other behavior variables such as the presence versus the absence of a brand upon choosing. Study the relevance of additive, interaction and double dissociation models to different purchase behaviors. 2. Study the processing and effects of variables specific to a message (humor, music...) on purchase behaviors, by segregating noetic from autonoetic awareness [98]. 3. Enhance the predictive validity of implicit measures, by developing priming techniques with a better access than IAT to implicit semantic representations associated with a brand.

Table 4 . Three research perspectives of the links between implicit attitude and behavior in a marketing communication context

For a given behavior, if the additive and interaction models are valid, predictive behavior measures should associate implicit and explicit measures. Even if, with IAT, implicit and explicit measures are positively correlated, each of them has an independent contribution to shaping behavior $[116,6]$. However, Poehlman et al. [129] show that, when there is an important dissociation between implicit and explicit measures, none of them, if taken individually, will have a strong predictive power. At a different level, implicit measures, more particularly the IAT, are even more relevant for and predictive of behavior when the response depends on the context, for instance when respondents must manage their selfimage (when products or topics are highly involving, taboos or involve socially-depreciated stereotypes). In this case, implicit and explicit measures of behavior are not correlated [130]. Leaving their contradictions aside, these results mainly concern attitudes, i.e. affective evaluations.

The third perspective focuses on taking research into predictive validity further on, by means of priming, which provides access to a larger network of implicit semantic representations associated with a brand, than IAT.

\section{Conclusion}

The first objective of the article was to show that the theoretical framework of the implicit attitude makes it possible to clarify the field of research on "non-conscious effects". We have shown that four types of effects produce implicit attitude change: a) non-conscious perception of brands, b) low-attention and forgotten exposures, c) attitude conditioning, d) brand insertion into emotional contexts. Secondly, because the theoretical and methodological framework of the implicit attitude is well adapted to study these types of effects, we have shown that research on the implicit attitudes opens new perspectives to study the persuasion in a marketing communication context. The main challenge lies therefore in developing more sensitive methods, able to measure the advertising efficiency via implicit tests of an appropriate theoretical and predictive validity. From a certain point of view, we can consider that the present article gives some basis to the field called by some people, "neuromarketing".

\section{References}

1. Shrum L J (2004) The Psychology of Entertainment Media: Blurring the lines between entertainment and persuasion. Lawrence Erlbaum

2. Gawronski B, De Houwer J (2014) Implicit measures in social and personality psychology. In: Handbook of research methods in social and personality psychology, 2nd edition, USA

3. Wittenbrink B, Schwarz N (2007) Implicit measures of attitudes. New York: Guilford Press USA.

4. Hassin RR, Uleman JS, Bargh JA (2005) The New Unconscious. Oxford: University Press USA.

5. Courbet D, Fourquet-Courbet MP, Kazan R, Intartaglia J (2014) The Longterm Effects of E-advertising: The Influence of Internet Pop-ups Viewed at a Low Level of Attention in Implicit Memory. J Comput-Mediat Comm 19: 274293.

6. Perkins A, Forehand M, Greenwald A, Maison D (2008) Measuring the non-conscious: Implicit social cognition on consumer behaviour. Handbook of Consumer Psychology 461-476.

7. Greenwald AG, Banaji MR (1995) Implicit Social Cognition: Attitudes, selfesteem and stereotypes. Psychol Rev 102: 4-27.

8. Dijksterhuis A, Aarts H, Smith PK (2005) The Power of the subliminal: On subliminal persuasion and Other potential applications. In: The New Unconscious 77-107.

9. Cheesman J, Merikle PM (1986) Distinguishing conscious from unconscious mental processes. Can J Psychology 40: 343-367.

10. Gawronski B, Bodenhausen GV (2006) Associative and propositional processes in evaluation: An integrative review of implicit and explicit attitude processes in evaluation: An integrative
change. Psychol Bull 132: 692-731.

11. Pham M T, Vanhuele M (1997) Analyzing the Memory Impact of Advertising Fragments. Market Lett 8: 407-417.

12. Glaser J, Kihlstrom JF (2005) Compensatory Automaticity: Unconscious Volition Is Not an Oxymoron. In: The New Unconscious USA 171-195. 
Citation: Courbet D, Fourquet-Courbet MP (2014) Non-conscious Effects of Marketing Communication and Implicit Attitude Change: State of Research and New Perspectives. Int J Journalism Mass Comm 1: 103. DOI: http://dx.doi.org/10.15344/2349-2635/2014/103

13. Janiszewski C (1988) Preconscious processing effects: The independence of attitude formation and conscious thought. J Consum Res 15: 199-209.

14. Janiszewski C (1993) Preattentive Mere Exposure Effects. J Consum Res 20: 376-392

15. Shapiro S, Heckler S E, Maclnnis DJ (1997) The Effects on Incidental Ad Exposure on the Formation of Consideration Sets. J Consum Res 24: 94-104.

16. Shapiro S (1999) When an Ad's Influence Is beyond Our Conscious Control: Perceptual and Conceptual Fluency Effects Caused by Incidental Ad Exposure. J Consum Res 26: 16-36.

17. Shapiro S, Maclnnis DJ, Heckler SE, Perez AM (1999) An experimental Method for studying unconscious perception in an marketing context. Psychol Mark 16: 459-477.

18. Perfect TJ, Edwards A (1998) Implicit memory for radio advertising. Psychol Rep 83: 1091-1094.

19. Vanhuele M, Courbet D, Denis S, Lavigne F, Borde A (2005) The effectiveness of non-focal exposure to web banners ads. Finanza Marketing e Produzione 23: $7-12$.

20. Zajonc B (1980) Feeling and Thinking: Preferences Need no Inferences. Am Psychol 35: 151-175.

21. Bornstein RF (1989) Exposure and Affect: Overview and meta-analysis of research 1968-1987. Psychol Bull 106: 265-289.

22. Holden SJ, Vanhuele M (1999) Know the Name, Forget the Exposure: Brand Familiarity versus Memory of Exposure Context. Psychol and Market 16: 479 486.

23. Pêtre A (2005) Mémorisation non consciente des publicités: apport d'une mesure implicite dans une application au netvertising. Rev Fr Marketing 201 23-47.

24. Shapiro S, Krishnan S (2001) Memory-Based Measures for Assessing Advertising Effects: A Comparison of Explicit and Implicit Memory Effects. Advertising 30: 1-30.

25. Courbet D (2003) L'influence publicitaire en l'absence de souvenir des messages: les effets implicites de la simple exposition ; The influence of advertising without message recall: the implicit effects of mere exposure. Cah Int advertising without mess
Psychol Soc 57: 39-51.

26. Nordhielm C L (2002) The influence of level of processing on advertising effects. J Consum Res 29: 371-382.

27. Mandler G (1980) Recognizing: The judgment of previous occurrence. Psychol Rev 87: 252-271.

28. Finlay K, Marmurek H, Morton R (2005) Priming effects in explicit and implicit memory for textual advertisements. Appl Psychol-Int Rev 54: 442-454.

29. Mäntylä T, Raudsepp J (1996) Recollective experience following suppression of focal attention. Eur J Cogn Psychol 8: 195-203.

30. Rajaram S (1993) Remembering and knowing: two means of access to the personal past. Mem Cognition 21: 89-102.

31. Dewhurst SA, Parry LA (2000) Emotionality, distinctiveness and recollective experience. Eur J Cogn Psychol 12: 541-551.

32. Lee AY (2001) The mere exposure effect: an uncertainty reduction explanation revisited. Pers Soc Psychol B 27: 1255-1266.

33. Janiszewski C, Meyvis T (2001) Effects of Brand Logo Complexity, Repetition and Spacing on Processing Fluency and Judgment. J Consum Res 28: 18-32.

34. Lee AY, Labroo AA (2004) The effects of conceptual and perceptual fluency on brand evaluation. J Marketing Res 41: 151-165.

35. Fazio RH (1990) A practical guide to the use of response latency in social psychological research. In: Hendrick C, Clark MS (Eds) Research methods in personality and social psychology, Newbury Park, USA. 74-97.

36. Roskos-Ewoldsen DR, Fazio RH (1992a) The accessibility of source likeability as a determinant of persuasion. Pers Soc Psychol B 18: 19-25.

37. Fazio RH, Dunton BC (1997) Categorization by race: The impact of automatic and controlled components of racial prejudice. J Exp Soc Psychol 69: 1013-1027.

38. Roskos-Ewoldsen DR, Fazio RH (1992b) On the orienting value of attitudes: Attitude accessibility as a determinant of an object's attraction of visual attention. J Pers Soc Psychol 63: 198-211.

39. Fazio RH, Williams CJ (1986) Attitude accessibility as a moderator of the attitude-perception and attitude-behavior relations: An investigation of the 1984 election. J Pers Soc Psychol 51: 505-514.
40. Berger IE, Mitchell AA (1989) The effect of advertising on attitude accessibility attitude confidence, and the attitude-behavior relationship. J Consum Res 16 : 269-279.

41. Schuette RA, Fazio RH (1995) Attitude accessibility and motivation as determinants of biased processing: A test of the MODE model. Pers Soc Psycho B 21: 704-710.

42. Walther E, Nagengast B, Trasselli C (2005) Evaluative conditioning in social psychology: Facts and speculations. Cogn Emot 19: 175-196.

43. Gorn GJ, Goldberg M E, Litvack D (1991) Music and Information in Commercials: Their effects with an Elderly Sample. J Advertising Res 31: 23-32.

44. Priluck R, Till BD (2004) The role of contingency awareness, involvement and need for cognition in attitude formation. J Acad Market Sci 32: 329-344.

45. Allen CT, Madden TJ (1985) A Closer Look at Classical Conditioning. J Consum Res 12: 301-315.

46. Stuart EW, Shimp TA, Engel RW (1991) A program of classical conditioning experiments testing variations in the conditioned stimulus and context. $\mathrm{J}$ Consum Res 18: 1-12.

47. Stuart EW, Shimp TA, Engel RW (1987) Classical conditioning of Consumer attitudes: four experiments in an advertising context. J Consum Res 14: 334-349.

48. Pechmann C, Stewart D W (1988) Advertising repetition: A critical review of wearin and wearout. Curr Iss Res Advertising 11: 285-329.

49. Grossman RP, Till BD (1998) The persistence of classically conditioned brand attitudes. J Advertising 27: 23-31.

50. Olson MA, Fazio RH (2001) Implicit Attitude Formation through Classical Conditioning. Psychol Sci 12: 413-417.

51. Walther E, Grigoriadis S (2004) Why sad people like shoes better: The influence of mood on the evaluative conditioning of consumer attitudes. Psycho Mark 21: 755-773.

52. Dempsey M A, Mitchell AA (2004) The Relation between Implicit and Explicit Attitudes and Spontaneous Choice. Adv Consum Res 31: 542.

53. Walther E (2002) Guilty by Mere Association: Evaluative Conditioning and the Spreading Attitude Effect. J Pers Soc Psychol 82: 919-934.

54. Fazio RH (2001) On the Automatic activation of associated Evaluations: An overview. Cogn Emot 15: 115-141.

55. Olson MA, Fazio RH (2002) Implicit Acquisition and Manifestation of Classically Conditioned attitudes. Soc Cogn 89-103.

56. Lipp OV, Purkis HM (2005) No support for dual process accounts of human affective learning to simple Pavlovian conditioning. Cogn Emot 19: 269-282.

57. Pleyers G, Corneille O, Luminet O, Yzerbyt V (2007) Aware and (Dis)Liking: Item-based Analyses Reveal that Valence Acquisition via Evaluative Conditioning emerges only when there is Contingency Awareness. J Exp Psychol Learn 33: $130-144$.

58. Meersmans T, De Houwer J, Baeyens F, Randell T, Eelen, P (2005) Beyond evaluative conditioning? Searching for associative transfer of nonevaluative stimulus properties. Cogn Emot 19: 283-306.

59. Kim J, Allen CT, Kardes FR (1996) An Investigation of the Mediational Mechanisms Underlying Attitudinal Conditioning. J Marketing Res 33: 318-328.

60. Baeyens F, Eelen P, Crombez G, Vandenbergh O (1992) Human evaluative conditioning: Acquisition trials, presentation schedule, evaluative style and contingency Awareness. Behav Res Ther 30: 133-142.

61. Meyers-Levy J, Sternthal B (1993) A Two-Factor Explanation of Assimilation and Contrast Effects. J Marketing Res 30: 359-368.

62. Mathur M, Chattopadhyay A (1991) The Impact of Moods Generated by Television Programs on Responses to Advertising. Psychol Mark 8: 59-77.

63. Goldberg M E, Gorn J (1987) Happy and Sad TV Programs: How they affect reactions to commercials. J Consum Res 14: 387-403.

64. Moorman M, Neijens PC, Smit EG (2002) The Effects of Magazine-Induced Psychological Responses and Thematic Congruence on Memory and Attitude Toward the Ad in a Real-Life Setting. J Advertising 31: 28-40.

65. Moorman M, Neijens PC, Smit E G (2005) The Effects of Program Responses on the Processing of Commercials Placed at Various Positions in the Program and the Block. J Advertising Res 45: 49-59.

66. Aylesworth AB, MacKenzie SC (1998) Context Is Key: The Effect of ProgramInduced Mood on Thoughts About the Ad. J Advertising 27: 17-33.
Int J Journalism Mass Comm

ISSN: $2349-2635$
IJJMC, an open access journal

Volume 1. 2014. 103 
Citation: Courbet D, Fourquet-Courbet MP (2014) Non-conscious Effects of Marketing Communication and Implicit Attitude Change: State of Research and New Perspectives. Int J Journalism Mass Comm 1: 103. DOI: http://dx.doi.org/10.15344/2349-2635/2014/103

67. Murry, JP, Dacin PA (1996) Cognitive Moderators of Negative-Emotion Effects: Implications for Understanding Media Context. J Consum Res 22: 439-447.

68. Soldow GF, Principe V (1981) Response to Commercials as a Function of Program Context. J Advertising Res 21: 59-65.

69. Pavelchak MA, Antil J H, Munch JM (1988) The Super Bowl: An Investigation into the Relationship among Program Context, Emotional Experience and Ad Recall. J Consum Res 15: 360-367.

70. Sonbonmatsu DM, Kardes FR (1988) The Effects of Physiological Arousal on Information Processing and Persuasion. J Consum Res 15: 379-385.

71. Shapiro S, Maclnnis DJ, Park CW (2002) Understanding Program-Induced Mood Effects: Decoupling Arousal from Valence. J Advertising, 31: 15-26.

72. De Pelsmacker P, Geuens M, Aiickaert P (2002) Media Context and Advertising Effectiveness: The Role of Context Appreciation and Context/Ad Similarity. J Advertising 31: 49-61.

73. Courbet $D$ (2000) Les effets automatiques du parrainage télévisuel sur la marque: étude de la mésattribution de la familiarité, du transfert sémantique et de l'influence des émotions déclenchées par le programme. Rech App Marke 15: $39-62$

74. Russell CA (1998) Toward a Framework of Product Placement Theoretical Propositions. Adv Consum Res 25: 357-362.

75. Law S, Braun KA (2000) I'll have what she's having: Gauging the impact of product placements on viewers. Psychol Mark 17: 1059-1075.

76. Fontaine I (2006) Etude du changement d'attitude pour les marques placées dans les films: persuasion ou effet d'exposition? Rech App Market 21: 1-18.

77. Russell CA (2002) Investigating the effectiveness of product placements in television shows: The role of modality and plot connection congruence on brand memory and attitude. J Consum Res 29: 306-318.

78. Yang M, Roskos-Ewoldsen B, Roskos-Ewoldsen DR (2004) Mental Models for Brand Placement. In: The Psychology of Entertainment Media, Blurring the lines between entertainment and persuasion Lawrence Erlbaum Associates 79 98.

79. Ellis HC, Moore BA (1999) Mood and Memory. In: Dalgleish T and Power M (Eds) Handbook of Cognition and Emotion England 193-210.

80. Mackie DM, Worth T (1991) Feeling Good, but not Thinking Straight: the Impact of Positive Mood on Persuasion. In: Emotion and social judgments, Pergamon Press, England 201-219.

81. Isen AM (1987) Positive Affect, Cognitive Processes and Social Behavior. Adv Exp Soc Psychol 20: 203-253.

82. Tavassoli NT, Schultz CJ, Fitzsimons GJ (1995) Program involvement: Are moderate levels best for ad memory and attitude toward the ad? J Advertising Res 35: 61-74.

83. Newell SJ, Henderso KV, Wu BT (2001) The effects of pleasure and arousa on recall of advertisements during the super Bowl. Psychol Mark 18: 1135-1153.

84. Hänze M, Meyer HA (1998) Mood influences on automatic and controlled semantic priming. Am J Psychol 111: 265-278.

85. Bless H, Schwarz N, Wieland R (1996) Mood and the impact of category membership and individuating information. Eur J Soc Psychol 26: 935-959.

86. Lee AY, Sternthal B (1999) The effects of positive moods on memory. J Consum Res 26: 115-127.

87. Schwarz N, Clore G L (1988) How do I feel about it? The informative function of affective states. In: Affect, Cognition and Social Behavior. 44-62.

88. Forgas JP, Bower GH (1988) Affect in social judgements. Aust J Psychol 40: 125-145.

89. Forgas JP (1995) Mood and Judgement: The Affect Infusion Model (AIM). Psychol Bull 117: 1-28.

90. Isen AM (1999) Positive affect. In: Handbook of Emotion and Cognition, Chichester. England 521-540.

91. Meyers-Levy J, Tybout AM (1997) Context Effects at Encoding and Judgemen in Consumption Settings: The Role of Cognitive Resources. J Consum Res 24 $1-14$.

92. Forehand M R, Perkins A (2005) Implicit Assimilation and explicit contrast: A Set/Reset Model of Response to Celebrity Voice-Overs. J Consum Res 32 435-441.

93. Strahan EJ, Spencer S, Zanna MP (2005) Subliminal Priming and Persuasion: How motivation affects the activation of Goals and the persuasiveness of messages. In: Applying Social Cognition to Consumer-Focused Strategy Lawrence Erlbaum Associates USA 267-280.
94. MacLeod C (1998) Implicit Perception: Perceptual Processing without Awareness. In: Implicit and Explicit Mental Processes 57-78.

95. Krishnan HS, Chakravarti D (2003) A Process Analysis of the Effects of Humorous Advertising Executions on Brand Claims Memory. J Consum Psycho 13: $230-245$

96. Merikle PM, Reingold EM (1998) On Demonstrating Unconscious Perception: Comment on Draine and Greenwald (1998). J Exp Psychol Gen 127: 304-310.

97. Holender D (1986) Semantic activation without conscious identification in dichotic listening, parafoveal vision and visual masking: A survey and appraisal. Behav Brain Sci 9: 1-66.

98. Tulving E (1995) Organization of memory: Quo vadis? In: The Cognitive neuroscience, Cambridge, MIT Press USA 839-847.

99. Allen CT, Janiszewski CA (1989) Assessing the role of contingency awareness in attitudinal conditioning with implications for advertising research. J Marketing Res 26: $30-43$

100. Yonelinas AP (1997) Recognition memory ROCs for item and associative information: The contribution of recollection and familiarity. Mem Cogn 25: 747 763.

101. Wheeler MA, Stuss DT, Tulving E (1997) Toward a theory of episodic memory: The frontal lobes and autonoetic consciousness. Psychol Bull 121: 331 354

102. Jacoby LL, Jennings JM, Hay LF (1996) Dissociating automatic and consciously controlled processes: Implications for Diagnosis and rehabilitation of memory deficits. In: Basic and Applied memory research: theory in context $161-193$

103. Bargh JA, Chartrand TL (1999) The Unbearable Automaticity of Everyday Life. Am Psychol 54: 462-479.

104. Fazio RH, Olson MA (2003) Implicit Measures in Social Cognition Research Their Meaning and Use. Annu Rev Psychol 54: 297-327.

105. Petty RE, Fazio RH, Briňol P (2007) Attitudes: Insights from the new wave of implicit measures.

106. Nosek BA., Greenwald AG, Banaji MR (2007) The Implicit Association Test at age 7: A methodological and conceptual review. In: Automatic processes in social thinking and behavior Psychology Press 265-292.

107. Kunst-Wilson WR, Zajonc RB (1980) Affective discrimination of Stimuli that cannot be recognized. Science 207: 557-558.

108. Jacoby LL (1998) Invariance in automatic influences of memory: toward a user's guide for the process-dissociation procedure. J Exp Psychol Learn 24 3-26.

109. Trendel O, Warlop L (2005) Présentation et application des mesures implicites de restitution mémorielle en marketing. Rech App Market 20: 77-104.

110. Dovidio JF, Fazio RH (1992) New technologies for the direct and indirect assessments of attitudes. In: Questions about Questions: Inquiries into the cognitive bases of surveys Russel Sage Foundation 204-237.

111. Gregg VH, Gardiner JM (1994) Recognition memory and awareness: A large effect of study-test modalities on "Know" responses following a highly orienting task. Eur J Cogn Psychol 6: 131-146.

112. Lee AY (2002) Effects on Implicit memory on memory-based versus stimulus-based brand choice. J Marketing Res 39: 440-454.

113. Brunel FF, Tietje BC, Greenwald AG (2004) Is the Implicit Association Test a Valid and Valuable Measure of Implicit Consumer Social Cognition? J Consum Psychol 14: 385-404.

114. Karpinski A, Steinman R B (2006) The Single Category Implicit Association Test as a Measure of Implicit Social Cognition. J Pers Soc Psychol 91: 16-32.

115. Trendel O, Warlop L (2005) Positive Implicit Effects for Event Incongruent Sponsorship. Adv Consum Res 32: 240-241.

116. Maison D, Greenwald AG, Bruin RH (2004) Predictive Validity of the Implicit Association Test in Studies of Brands, Consumer Attitudes, and Behavior. J Consum Psychol 14: 405-415.

117. Greenwald A, Nosek BA, Banaji MR (2003) Understanding and Using the Implicit Association Test: I. An Improved Scoring Algorithm. J Pers Soc Psychol 85: $197-216$

118. Kim D (2004) The Implicit Life Satisfaction measure (ILS). Asian J Soc Psychol 7: 236-243.

119. Gawronski B, Bodenhausen GV (2005) Accessibility Effects on Implicit Social Cognition: The Role of Knowledge Activation and Retrieval Experiences. $J$ Pers Soc Psychol 89: 672-685. 
Citation: Courbet D, Fourquet-Courbet MP (2014) Non-conscious Effects of Marketing Communication and Implicit Attitude Change: State of Research and New Perspectives. Int J Journalism Mass Comm 1: 103. DOI: http://dx.doi.org/10.15344/2349-2635/2014/103

120. Devine PG (1989) Stereotypes and prejudice: Their automatic and controlled components. J Pers Soc Psychol 56: 5-18.

121. Wilson TD, Lindsey S, Shooler TY (2000) A Model of Dual Attitude. Psychol Rev 107: 101-126.

122. Greenwald AG, McGhee DE, Schwarz JL (1998) Measuring Individuals Differences in Implicit Cognition: The Implicit Association Test. J Pers Soc Psychol 74: 1464-1480.

123. Fazio RH, Towles-Schwen, T (1999) The MODE Model of Attitude-Behavior Process. In: Dual-Process Theories in Social Psychology The Guilford Press 97

124. Fazio RH, Powell, M C, Williams CJ (1989) The role of attitude accessibility in the attitude-to-behavior process. J Consum Res 16: 280-288.

125. Glasman LR, Albarracin D (2006) Forming attitudes that predict behavior: A Meta-Analysis of the attitude-behavior relation. Psychol Bull 132: 778-822.

126. Perugini M (2005) Predictive models of implicit and explicit attitudes. Brit Soc Psychol 44: 29-45.

127. Rydell R, McConnell AR (2006) Understanding implicit and explicit attitude change: A systems of reasoning analysis. J Pers Soc Psychol 91: 995-1008.

128. Friese $M$, Wänke $M$, Henning $P(2006)$ Implicit consumer preferences and their influence on product choice. Psychol Mark 23: 727-740.

129. Poehlman A, Uhlmann E, Greenwald AG, Banaji MR (2005) Understanding and using the IAT: III. Meta-analysis of predictive validity. J Pers Soc Psycho 97: $17-41$

130. Maison D, Greenwald AG, Bruin RH (2001) The Implicit Association Test as a measure of implicit consumer attitudes. Pol Psychol Bull 32: 61-70. 